\title{
Large-Scale Environmental Characteristics of MJOs that Strengthen and Weaken over the Maritime Continent ${ }^{\circ}$
}

\author{
Casey D. Burleyson, Samson M. Hagos, and Zhe Feng \\ Pacific Northwest National Laboratory, Richland, Washington \\ BRANDON W. J. KERNS AND DAEHYUN KIM \\ University of Washington, Seattle, Washington
}

(Manuscript received 25 August 2017, in final form 13 April 2018)

\begin{abstract}
The characteristics of Madden-Julian oscillation (MJO) events that strengthen and weaken over the Maritime Continent (MC) are examined. The real-time multivariate MJO (RMM) index is used to assess changes in global MJO amplitude over the MC. The MJO weakens at least twice as often as it strengthens over the MC, with weakening MJOs being twice as likely during El Niño compared to La Niña years and the reverse for strengthening events. MJO weakening shows a pronounced seasonal cycle that has not been previously documented. During the Northern Hemisphere $(\mathrm{NH})$ summer and fall the RMM index can strengthen over the MC. MJOs that approach the MC during the NH winter typically weaken according to the RMM index. This seasonal cycle corresponds to whether the MJO crosses the MC primarily north or south of the equator. Because of the seasonal cycle, weakening MJOs are characterized by positive sea surface temperature and moist-static energy anomalies in the Southern Hemisphere $(\mathrm{SH})$ of the MC compared to strengthening events. Analysis of the outgoing longwave radiation (OLR) MJO index (OMI) shows that MJO precipitation weakens when it crosses the MC along the equator. A possible explanation of this based on previous results is that the $\mathrm{MJO}$ encounters more landmasses and taller mountains when crossing along the equator or in the SH. The new finding of a seasonal cycle in MJO weakening over the MC highlights the importance of sampling MJOs throughout the year in future field campaigns designed to study MJO-MC interactions.
\end{abstract}

\section{Introduction}

Convection associated with the Madden-Julian oscillation (MJO) often weakens, stalls, or completely dissipates as it crosses the Maritime Continent (MC; Fig. 1) region separating the Indian and Pacific Oceans (e.g., Rui and Wang 1990; Salby and Hendon 1994; Kim et al. 2014; Hagos et al. 2016; Kerns and Chen 2016; Zhang and Ling 2017). The weakening effect is exaggerated in numerical models compared to observations (Kim et al. 2009; Jiang et al. 2015). This interaction between the MC and the eastward propagation of the MJO

Supplemental information related to this paper is available at the Journals Online website: https://doi.org/10.1175/JCLI-D-170576.s1.

Corresponding author: Dr. Casey D. Burleyson, casey.burleyson@ pnnl.gov is commonly referred to as the MC "barrier effect"a topic that has been the focal point of numerous recent studies (e.g., Seo et al. 2009; Vitart and Molteni 2010; Hirata et al. 2013; Kim et al. 2014; Feng et al. 2015; Hagos et al. 2016; Kerns and Chen 2016; Zhang and Ling 2017). Generally speaking, these studies have focused on understanding the physical processes through which the MC islands affect the MJO. Specifically, they target processes that are absent in the open-ocean regions of the eastern Indian and western Pacific Oceans where the barrier effect is less pronounced. This study addresses the related question of why some MJO episodes intensify over the MC while others weaken.

Several previous studies laid the groundwork for our investigation. Maloney and Sobel (2004) and Sobel et al. (2008) highlighted the importance of surface latent heat fluxes under the main convective envelope of the MJO. In their proposed framework, the islands of the MC limit the overall latent heat fluxes and thus the MJO weakens. 


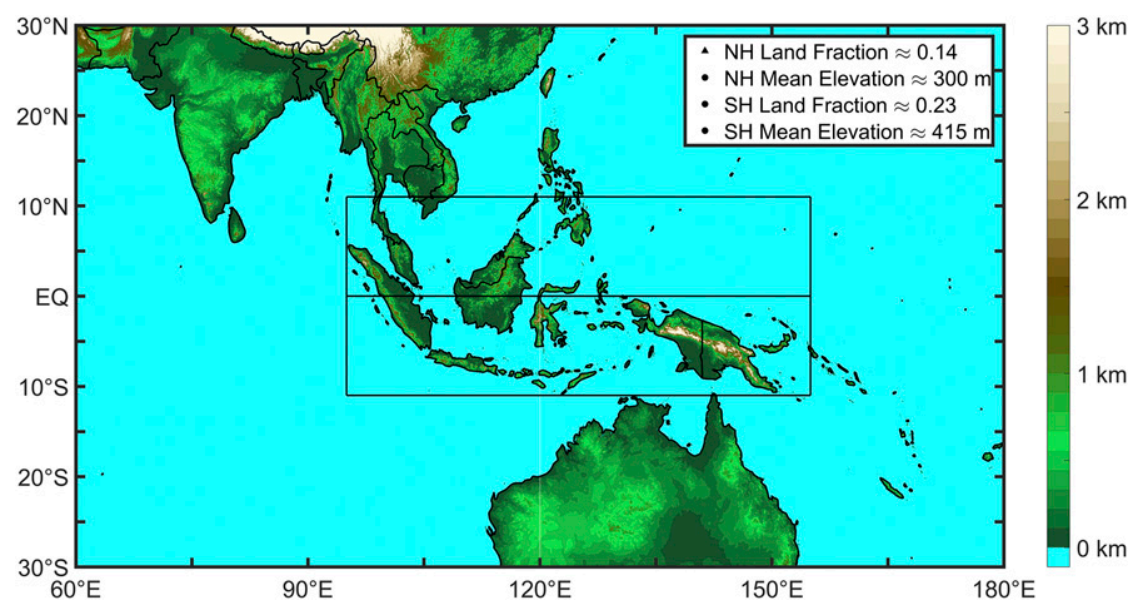

FIG. 1. Elevation of the islands of the MC. The black rectangles denote the NH and SH domains we use for averaging throughout the paper.

Under the moisture mode theoretical framework of the MJO (Raymond 2001; Sobel and Maloney 2012, 2013; Adames and Kim 2016) in which the propagation is facilitated by horizontal moist static energy (MSE) advection (positive MSE advection east of the MJO and negative MSE advection west of the MJO), the propagation is stalled if the islands limit the generation of MSE ahead of the main convective envelope. More recent papers have suggested that the diurnal cycle of convection over the islands of the MC interrupts the "rhythm" of the MJO and may stall its propagation (Hagos et al. 2016).

Two studies have used precipitation tracking methods to quantify the frequency and characteristics of the barrier effect. Kerns and Chen (2016; hereinafter KC16) tracked large regions of precipitation in the TRMM 3B42 dataset to identify MJOs that cross (MC crossing) and stall over the MC (non-MC crossing). Their primary finding was that only 24 of the 48 features they tracked successfully crossed the MC. Using a similar approach, Zhang and Ling (2017; hereinafter ZL17) found that roughly half of the MJOs they tracked crossed the MC, but $75 \%$ of those that did cross were substantially weakened over the MC.

Previous studies have mostly focused on the barrier effects of the MC during boreal winter, leaving the effects during boreal summer an unexplored area. A recent paper by Liu et al. (2016) did explore the role of El Niño-Southern Oscillation (ENSO) in modifying the propagation of intraseasonal oscillations over the MC during the boreal summer. They found that during $\mathrm{La}$ Niña years, MJO events initiated in the Indian Ocean are more likely to propagate over the $\mathrm{MC}$ because of more favorable moisture conditions compared to $\mathrm{El}$ Niño years. The MJO exhibits a pronounced seasonal cycle; the main convective envelope associated with the MJO detours the MC southward during boreal winter while the MJO propagates primarily north of the MC during boreal summer (Zhang and Dong 2004). While the mechanism for the southward and northward detouring of the MJO around the MC has been studied (Adames et al. 2016; Kim et al. 2017), the possible differences in the MC barrier effects between the two seasons has not been fully explored.

We aim to build on this body of work by addressing a related, but relatively unexplored, aspect of the MC barrier effect: What are the environmental conditions for MJOs that strengthen over the MC and in what ways are they different from MJOs that weaken over the MC? Are there systematic seasonal differences in the rate at which MJO weakens or strengthens? To address these questions, we first examine strengthening and weakening MJO events across the seasonal cycle. We then examine large-scale environmental conditions such as sea surface temperatures (SSTs), moist static energy, precipitation, and upper-level divergence associated with those strengthening and weakening events. Understanding these differences will improve our understanding of the MJO propagation mechanism, help to explain the MC barrier effect, and ultimately move toward improved understanding of predictability and the source of model prediction skills.

\section{Data and methods}

As stated in the introduction, the crux of our methodology involves identifying cases where the MJO strengthens and weakens over the MC and then analyzing differences in composite environmental variables between the two. As such, our method for identifying strengthening and weakening MJOs is crucial to our 
(a)

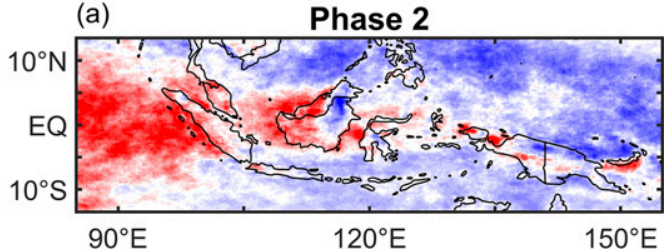

(b)

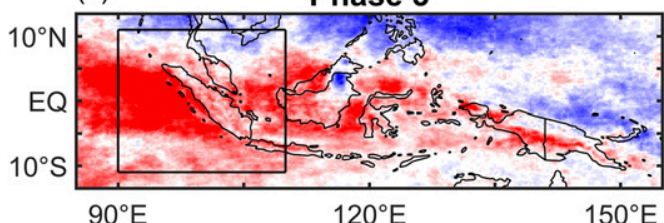

$90^{\circ} \mathrm{E}$

(c)

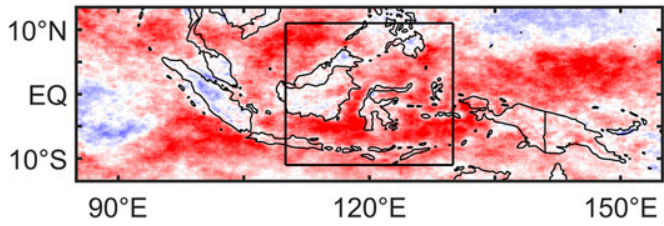

(d)

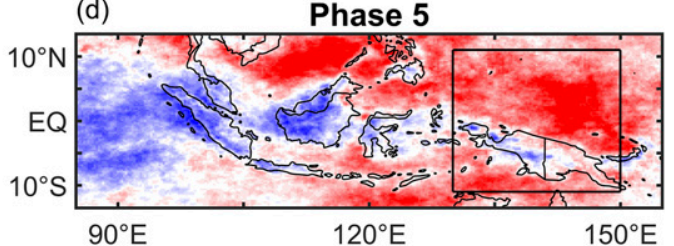

(e)

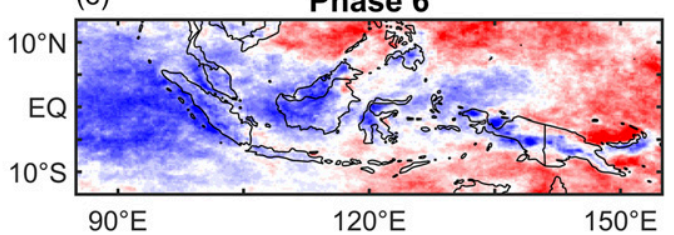

$120^{\circ} \mathrm{E}$

FIG. 2. Precipitation anomalies over the MC for (a)-(e) RMM phases 2-6. Anomalies were computed with respect to periods when the RMM amplitude was $<1$. [The black boxes in (b)-(d) outline the averaging areas used to compute the mean rain-rate anomaly values in Fig. 4.]

overall ability to discern $\mathrm{MC}$ impacts on the strength of the MJO. Our main dataset for the classification is the time series of the real-time multivariate MJO (RMM; Wheeler and Hendon 2004) index. We use the daily RMM index from 1974 to 2013. We obtained the data from the Australian Bureau of Meteorology (http://www. bom.gov.au/climate/mjo/graphics/rmm.74toRealtime.txt; accessed on 13 January 2016). Based on empirical orthogonal functions of the zonal winds at 850 and $200 \mathrm{hPa}$ as well as satellite measurements of outgoing longwave radiation (OLR), the RMM index has a phase and amplitude that correspond to the location and strength/ coherency of the MJO, respectively. The RMM index is a commonly used metric for identifying and studying the MJO. Its widespread acceptance in the community and easy interpretability are two key reasons we selected it for this study. The amplitude of the RMM index reflects the global strength of the MJO, particularly in the uppertropospheric zonal wind field (Straub 2013). While the amplitude is not always effective for understanding individual events, averaging over multiple events spanning many years enhances the robustness of our results. Because the precipitation tracking algorithms of $\mathrm{KC} 16$ and ZL17 track local precipitation anomalies, it is worthwhile to revisit their findings using a global index such as RMM, which captures the global MJO signal.

Under the RMM index, the MJO approaches the MC in phases $2-3$, is over the center of the MC in phase 4 , and exits the MC in phases 5-6. Figure 2 shows the mean precipitation anomaly over the MC for each of these phases, conditioned on the amplitude of the RMM index being $\geq 1$, a commonly used threshold for identifying coherent MJO signals with a robust phase (e.g., Straub 2013; Kiladis et al. 2014). Similar plots for each season are included in Figs. S1-S5 of the supplemental material. The close association between the RMM phase and the location of positive precipitation anomalies over the MC is clear. Figure 2 also shows that most of the positive precipitation anomalies associated with the MJO occur over water-as previously demonstrated by, for example, Wu and Hsu (2009). We use changes in the amplitude of the RMM index between phases 3 and 5 to identify MJOs that strengthen or weaken over the MC.

We use the following conditions to classify candidate MJO events:

1) Identify a date in the RMM index time series in which the phase 3 amplitude is $\geq 1$. This date is labeled $t_{0}$. The purpose of this condition is to ensure that the MJO is coherent as it approaches the MC.

2) If condition 1 is met, the next 30 days of the time series are searched to see if the MJO proceeds through phases 4-6. We do not require that the amplitude is $\geq 1$ in each phase, only that the index identifies each of the next 3 phases at some point in the $t_{0}+30$-day period after condition 1 is met. This decision does not impact our primary conclusions 

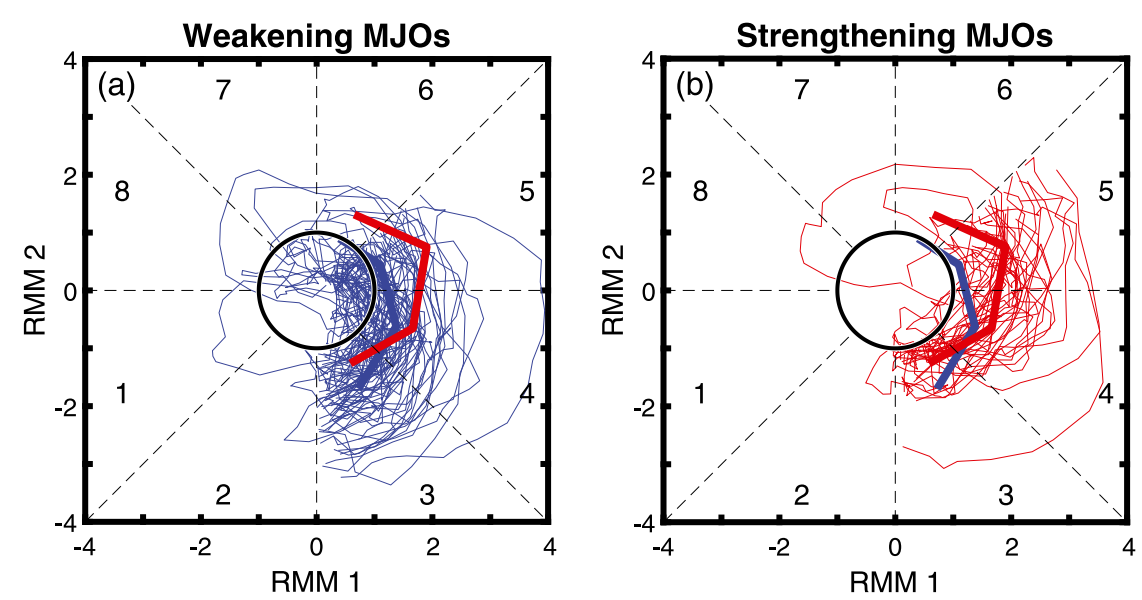

FIG. 3. The RMM 1 and 2 amplitudes for cases in which the MJO (a) weakens and (b) strengthens across the MC. Each thin line traces the evolution of an individual MJO event. The thick lines show the mean amplitude for each phase and are repeated in both panels for comparison.

(not shown). We do not use any threshold for the length of time each phase occurs during the $t_{0}+$ 30-day period, meaning that the MJO is included in our sample even if it only spends 1 day each in phases 4-6. The purpose of this condition is to establish that the MJO continues to propagate, even if weakened, across the MC.

3) If conditions 1 and 2 are met, the $t_{0}+30$-day time series is used to compute the mean amplitude of the RMM index for each phase from 3 to 6 . The purpose of this condition is to quantify the strength and coherence of the MJO as it crosses the MC.

We define MJO weakening events as those in which the mean RMM amplitude decreases by more than 0.25 between phases 3 and 5. Likewise, MJO strengthening events are defined as those in which the mean RMM amplitude increases by more than 0.25 between phases 3 and 5. All other cases in which the mean RMM amplitude changes by less than \pm 0.25 are classified as neutral MJO events. We classify every candidate MJO event in the 1974-2013 time frame as either strengthening, weakening, or having neutral changes over the MC. Over this 40-yr sample, there were $72 \mathrm{MJO}$ events classified as weakening, 35 events classified as strengthening, and 42 cases in which the MJO neither strengthened nor weakened across the MC. These sample sizes reflect the observation that the MJO most often weakens across the MC. ZL17 found that $75 \%$ of incoming MJOs are weakened over the MC. In our dataset, MJO weakening occurs roughly twice as often as MJO strengthening across the MC. The evolution of the RMM index for MJO strengthening and weakening cases is shown using the standard RMM phase diagram in Fig. 3. The distributions of RMM amplitudes during phases 3-6 for MJO weakening, strengthening, and neutral cases are also shown in Fig. S6 of the supplemental material. In many of the MJO weakening cases (Fig. S6b), the RMM amplitude falls below 1 in phases $4-6$. In other words, these MJO events essentially become incoherent or simply dissipate as they encounter the MC.

As our criteria for identifying weakening and strengthening MJOs are admittedly somewhat arbitrary, it makes sense to check if they actually capture changes in the strength of the MJO across the MC. To evaluate this, we calculated the mean rain-rate anomaly for RMM phases 3-5 for MJO cases we identified as either strengthening, weakening, or having neutral changes across the MC according to the global RMM index. The area over which the rain rate was calculated moves with the position of the MJO (Figs. 2b-d). For each MJO event, we subtracted out the monthly mean background rain rate for non-MJO periods (i.e., RMM amplitude $<1$ ) to account for longitudinal gradients in precipitation across the MC. In general there is more rainfall on the eastern side of the MC compared to the western side, so there is a background increase in rainfall from the phase 3 to the phase 5 boxes in this calculation (not shown).

Changes in the mean rain-rate anomaly for strengthening, weakening, and neutral MJO cases are shown in Fig. 4a. Changes in the distribution of rain-rate anomalies across the MC are consistent with our classifications of weakening and strengthening MJO events. For MJO weakening cases, the 50th and 75th percentiles of rain-rate anomalies during phase 5 are lower compared to the equivalent percentiles during phase 3 . The MJO 
Total Rainrate Anomaly

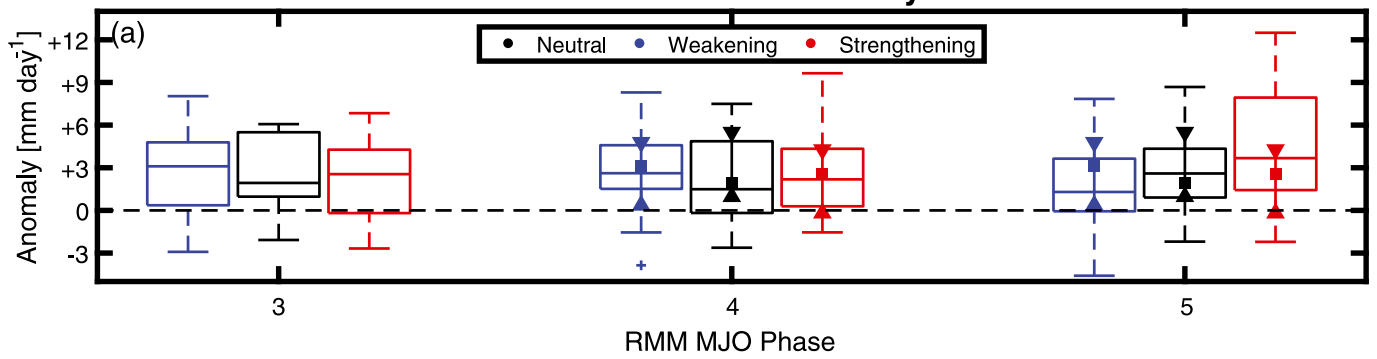

Hemispheric Rainrate Anomaly

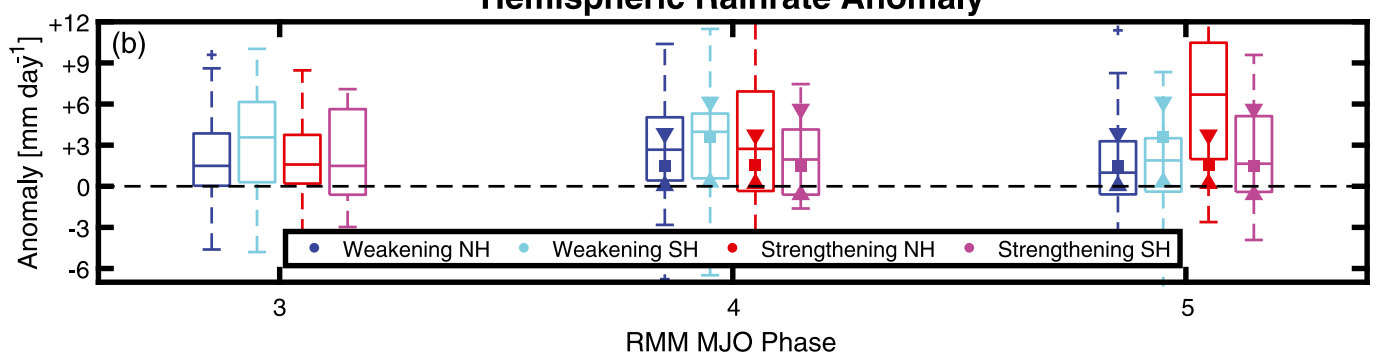

FIG. 4. Box-and-whisker plots showing the distribution of the (a) total and (b) hemispheric mean rain-rate anomaly during RMM phases 3-5 for MJO cases that weaken, strengthen, or have neutral changes over the MC. Anomalies are computed by removing the monthly mean rain rate from each sample. Solid horizontal lines in the boxes indicate the 25 th, 50 th, and 75 th percentiles of each distribution and the whiskers extend to \pm 2.7 standard deviations from the mean. For RMM phases 4 and 5, the phase 3 percentiles for the corresponding groups are indicated by the solid markers. The averaging boxes for each phase are shown in Fig. 2 and the distributions are divided into the $\mathrm{NH}$ and $\mathrm{SH}$ portions of the $\mathrm{MC}$ in (b).

strengthening cases are characterized by large positive increases in every quartile of the rain-rate anomaly distribution. Breaking down the anomalies by hemisphere shows that most of the rain rate decreases for MJO weakening cases occur in the Southern Hemisphere $(\mathrm{SH})$, while rain rate increases for $\mathrm{MJO}$ strengthening cases occur primarily in the Northern Hemisphere (NH) of the MC (Fig. 4b). These patterns will be explored later in the analysis. The net result of this rainfall anomaly analysis is that we can be confident that our simple classification scheme using the global RMM index, which has the added benefit of being easy to understand and reproduce, is able to separate MJO events that strengthen from those that weaken over the MC. Figure 4 also shows that neutral MJO events are statistically indistinguishable from weakening MJO events. For this reason we focus our analysis on the differences between weakening and strengthening MJOs.

The final step in our methodology is to composite environmental variables that might physically explain the differences among our two classes of data. Using MJO weakening cases as an example, to create the composites for $\mathrm{MJO}$ weakening we take the starting and ending dates for all $72 \mathrm{MJO}$ weakening events and identify periods when the RMM index was in phases $3-6$. To create the phase 4 composites, which are used throughout our results section, we took the average of a set of environmental variables for all days within the MJO weakening date ranges when the RMM index was in phase 4 . The environmental variables we investigated are either based on satellite data (precipitation frequency, rain rate, and SSTs) or reanalyses (200-hPa divergence and column-integrated MSE). These environmental variables reflect both the impact of the background environment on the MJO (SSTs and MSE) and the impact of the MJO on the environment (precipitation and upper-level divergence). Satellite and reanalysis datasets were chosen because they have uniform coverage over the $\mathrm{MC}$ and relatively long data records. The characteristics of each dataset we used are summarized in Table 1. All of the data products we utilized have a daily or higher temporal resolution. The temporal range of data available in each dataset is not uniform. The precipitation and SST measurements from satellite are only available in the TRMM era (1998-2013).

We quantify significant differences in the composite variables for $\mathrm{MJO}$ strengthening and weakening cases by evaluating the statistical significance of the differences between the two using a two-sample Welch's $t$ test. The significance tests evaluate whether or not the mean values for strengthening and weakening MJO cases are different from each other with $95 \%$ confidence $(p=0.05)$. Because 
TABLE 1. A summary of the various datasets used in our analysis.

\begin{tabular}{|c|c|c|c|c|c|}
\hline Variable & Dataset & $\begin{array}{l}\text { Period } \\
\text { utilized }\end{array}$ & $\begin{array}{l}\text { Native spatial } \\
\text { resolution }\end{array}$ & $\begin{array}{l}\text { Native temporal } \\
\text { resolution }\end{array}$ & Reference \\
\hline RMM index & RMM index & 1979-2014 & - & Daily & Wheeler and Hendon (2004) \\
\hline OLR MJO index & OLR MJO index & 1979-2016 & - & Daily & Kiladis et al. (2014) \\
\hline $\begin{array}{l}\text { Sea surface } \\
\text { temperature (SST) }\end{array}$ & $\begin{array}{l}\text { Remote Sensing Systems' } \\
\text { optimally interpolated (OI) } \\
\text { microwave and IR SST }\end{array}$ & $2002-14$ & $\sim 9 \mathrm{~km} \times 9 \mathrm{~km}$ & Daily & Reynolds and Smith (1994) \\
\hline $\begin{array}{l}\text { Precipitation frequency } \\
\text { and rain rate }\end{array}$ & TRMM 3B42 & $1998-2014$ & $0.25^{\circ} \times 0.25^{\circ}$ & $3 \mathrm{~h}$ & Huffman et al. (2007) \\
\hline 200-hPa divergence & ERA-Interim & 1979-2014 & $\sim 80 \mathrm{~km} \times 80 \mathrm{~km}$ & $6 \mathrm{~h}$ & Dee et al. (2011) \\
\hline Moist static energy & ERA-Interim & 1979-2014 & $\sim 80 \mathrm{~km} \times 80 \mathrm{~km}$ & Daily & Dee et al. (2011) \\
\hline $\begin{array}{l}\text { Outgoing longwave } \\
\text { radiation (OLR) }\end{array}$ & NOAA interpolated OLR & 1974-2014 & $2.50^{\circ} \times 2.50^{\circ}$ & Daily & Liebmann and Smith (1996) \\
\hline
\end{tabular}

the sample sizes underlying the strengthening and weakening composites are modest and often different, the tests are performed without assuming equal variance between the two classes. Data points in each of the difference maps for the following figures that are statistically different are marked with crosses. To evaluate hemispheric differences between strengthening and weakening cases, we calculate averages for each variable for the $\mathrm{NH}$ and $\mathrm{SH}$ areas of the MC. The extent of these averaging domains is shown in Fig. 1 and are repeated in map figures throughout the paper. The mean values for each hemisphere are reported in Table 2. We also test the statistical significance of the $\mathrm{NH}$ and $\mathrm{SH}$ averages (i.e., are the means statistically different than 0?) using a Welch's $t$ test statistic.

\section{Results}

\section{a. Environmental characteristics of weakening and strengthening MJOs}

The first variable we examine in our search for causes of MJO-weakening over the MC is SSTs. Figure 5 shows the mean SST during RMM phase 4 for MJO weakening and strengthening cases as well as the difference between the two. Because the SST data are only available from 2002 to 2014, the sample size of MJO weakening $(N=22)$ and strengthening $(N=12)$ cases is smaller than the samples available from the full RMM index time series. The most obvious difference in SSTs between MJO strengthening and weakening cases is the presence of warmer SSTs in the SH for MJO weakening cases. The mean temperature difference is $+0.53^{\circ} \mathrm{C}$ in the SH (Table 2), with positive differences at individual points as high as $+1.3^{\circ} \mathrm{C}$. The difference is statistically significant for $15 \%$ of data points in the $\mathrm{SH}$ portion of the $\mathrm{MC}$, particularly in the Java Sea $\left(\sim 5^{\circ}-10^{\circ} \mathrm{S}, 105^{\circ}-\right.$ $\left.125^{\circ} \mathrm{E}\right)$. Because the likelihood that small differences are statistically significant is inversely proportional to the sample size, the fact that the SSTs are statistically different even with relatively few samples is indicative of consistently positive SST anomalies in the SH. Out of the $22 \mathrm{MJO}$ weakening cases in the SST dataset, 15 cases $(68 \%)$ had a mean SST in the SH that was at least $0.25^{\circ} \mathrm{C}$ warmer than the mean SH SST for MJO strengthening

TABLE 2. Mean values of various environmental parameters in the NH and SH portions of the MC for MJOs that weaken or strengthen over the MC. Values with an asterisk in the difference column are statistically different from 0 at $p=0.05$. The far-right columns give the sample sizes for weakening and strengthening MJOs observed in each dataset.

\begin{tabular}{|c|c|c|c|c|c|c|}
\hline \multirow[b]{2}{*}{ Variable (units) } & \multirow[b]{2}{*}{ Domain } & \multirow{2}{*}{$\begin{array}{c}\text { MJO } \\
\text { weakening }\end{array}$} & \multirow{2}{*}{$\begin{array}{c}\text { MJO } \\
\text { strengthening }\end{array}$} & \multirow{2}{*}{$\begin{array}{l}\text { Difference (weakening } \\
\text { minus strengthening) }\end{array}$} & \multicolumn{2}{|c|}{ Sample size $(N)$} \\
\hline & & & & & Weakening & Strengthening \\
\hline \multirow{2}{*}{$\begin{array}{l}\text { Sea surface } \\
\quad \text { temperature }\left({ }^{\circ} \mathrm{C}\right)\end{array}$} & $\mathrm{NH}$ & 29.12 & 29.10 & $+0.02 *$ & \multirow[t]{2}{*}{22} & \multirow[t]{2}{*}{12} \\
\hline & SH & 29.22 & 28.69 & $+0.53 *$ & & \\
\hline \multirow{2}{*}{$\begin{array}{l}\text { Precipitation } \\
\quad \text { frequency }(\%)\end{array}$} & $\mathrm{NH}$ & 25.18 & 28.89 & $-3.72 *$ & \multirow[t]{2}{*}{29} & \multirow[t]{2}{*}{16} \\
\hline & SH & 25.80 & 21.20 & $+4.60 *$ & & \\
\hline \multirow[t]{2}{*}{ Rain rate $\left(\mathrm{mm}^{-1 a y}{ }^{-1}\right)$} & $\mathrm{NH}$ & 9.36 & 10.80 & $-1.44 *$ & \multirow[t]{2}{*}{29} & \multirow[t]{2}{*}{16} \\
\hline & SH & 10.38 & 8.28 & $+2.10 *$ & & \\
\hline \multirow[t]{2}{*}{ 200-hPa divergence $\left(\mathrm{s}^{-1}\right)$} & $\mathrm{NH}$ & $2.55 \times 10^{-6}$ & $3.20 \times 10^{-6}$ & $-0.65 \times 10^{-6 *}$ & \multirow[t]{2}{*}{65} & \multirow[t]{2}{*}{34} \\
\hline & $\mathrm{SH}$ & $3.13 \times 10^{-6}$ & $2.25 \times 10^{-6}$ & $0.88 \times 10^{-6 *}$ & & \\
\hline \multirow[t]{2}{*}{ Moist static energy $(\mathrm{J})$} & $\mathrm{NH}$ & $6.11 \times 10^{6}$ & $6.13 \times 10^{6}$ & $-1.47 \times 10^{4 *}$ & \multirow[t]{2}{*}{65} & \multirow[t]{2}{*}{34} \\
\hline & SH & $6.12 \times 10^{6}$ & $6.12 \times 10^{6}$ & $0.14 \times 10^{4} *$ & & \\
\hline
\end{tabular}



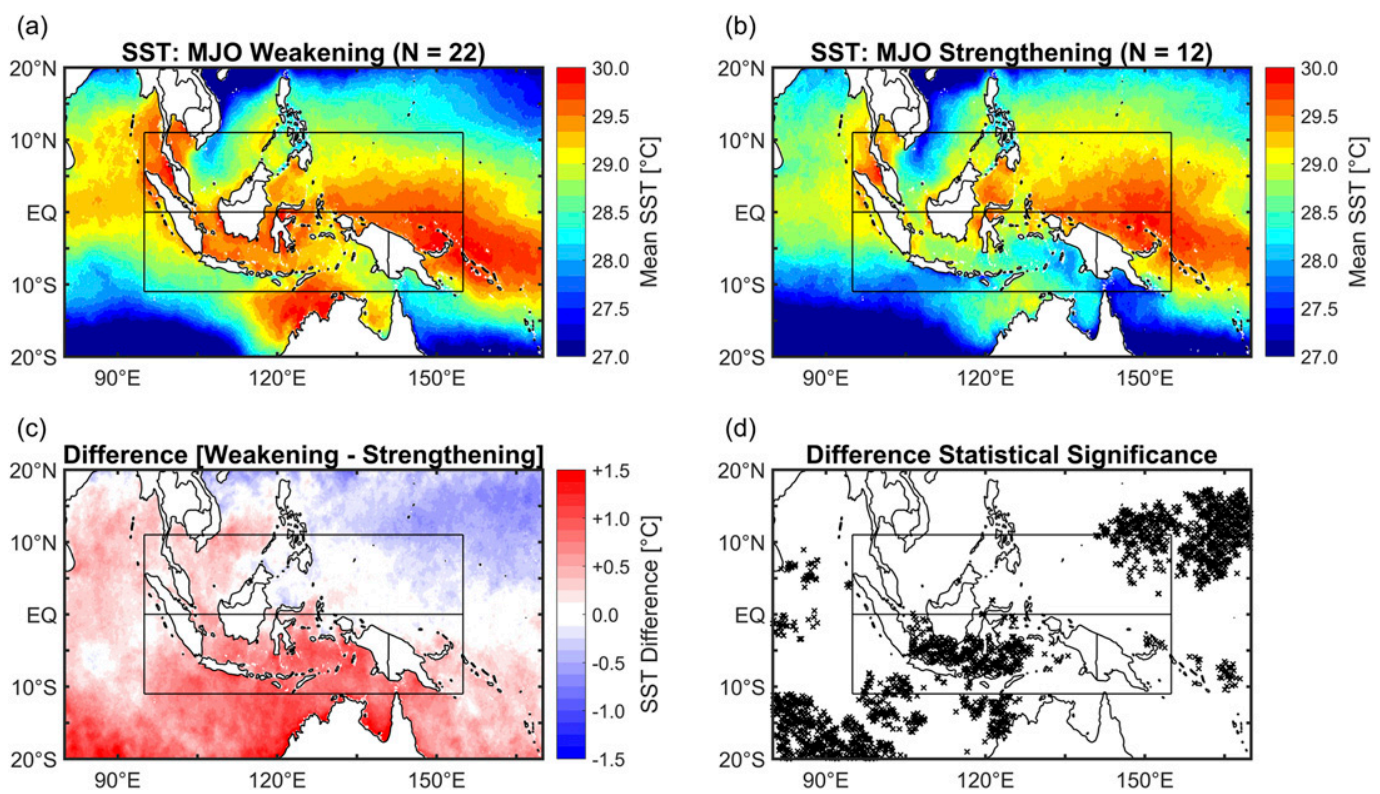

FIG. 5. The mean SST during RMM phase 4 for cases in which the MJO (a) weakens and (b) strengthens across the MC. (c) The difference between weakening and strengthening cases. (d) Crosses indicate areas where the means are statistically different at $p=0.05$.

cases. In contrast, the mean SST difference in the $\mathrm{NH}$ was only $+0.02^{\circ} \mathrm{C}$ and only $3.5 \%$ of the data points in the $\mathrm{NH}$ were statistically different between MJO strengthening and weakening cases.

While outside of the MC, Fig. 5 also shows statistically significant SST differences in the southwest (warmer SSTs for MJO weakening cases) and northeast (colder SSTs for MJO weakening cases) corners of the domain we examine. This dipole across the MC may reflect the role of ENSO in driving changes in the strength of the MJO across the MC, as El Niño events are typically characterized by colder-than-normal SSTs in the western Pacific (Jia et al. 2016, their Fig. 2a). Breaking down our neutral, strengthening, and weakening MJO events by ENSO phase confirms this pattern (Fig. 6). We determined the phase of ENSO using the oceanic Niño index (ONI), which is calculated over the Niño-3.4 region of the central Pacific. We use the standard ONI threshold of $+0.5^{\circ}$ and $-0.5^{\circ} \mathrm{C}$ to classify El Niño and La Niña events, respectively. Time periods with $|\mathrm{ONI}|<$ $0.5^{\circ} \mathrm{C}$ are considered to be ENSO neutral. If ENSO had no impact on the strength of the MJO as it crosses the MC then we would expect a priori that the number of times each ENSO phase occurs for each of our classes of MJOs is similar to the raw sample sizes of El Niño and La Niña events in the 40-yr data record (e.g., roughly 1.3 El Niño events for every $1 \mathrm{La}$ Niña event). However, Fig. 6 shows that weakening MJO events occur exactly twice as often during El Niño years compared to La Niña years. In contrast, strengthening MJOs in our classification system are nearly twice as likely to occur during La Niña years compared to El Niño years. The latter result is likely due to the positive SST anomalies and enhanced upper-level divergence over the MC during La Niña periods (see Fig. S7 in the supplemental material; see also Fig. 2c in Jia et al. 2016). These results are broadly consistent with $\mathrm{KC16}$, who found that MCcrossing events were observed more often during La Niña years compared to El Niño years. ZL17 did not find a significant impact from ENSO on MC-crossing or blocked events. Our result is also consistent with Liu et al. (2016), who found that eastward-propagating intraseasonal oscillations occurring during the $\mathrm{NH}$ summer tend to traverse the MC more commonly during $\mathrm{La}$ Niña years compared to El Niño years.

The north-south dipole in SSTs is reflected in the mean column-integrated MSE maps for MJO strengthening and weakening cases (Fig. 7). MJOs in which the RMM index weakens over the MC are characterized by persistently smaller MSE in the NH and weakly positive MSE anomalies in some parts of the SH compared to MJO strengthening cases. When examining the mean values though, the $\mathrm{NH}$ had a mean MSE anomaly $\left(-1.47 \times 10^{4} \mathrm{~J}\right)$ that was statistically different from 0 (Table 2). On a point-by-point basis, statistically significant differences are confined to the far north region of the $\mathrm{MC}$ in the $\mathrm{NH}$ and more broadly to areas north of $10^{\circ} \mathrm{N}$ across much of the domain we examined. The lack 


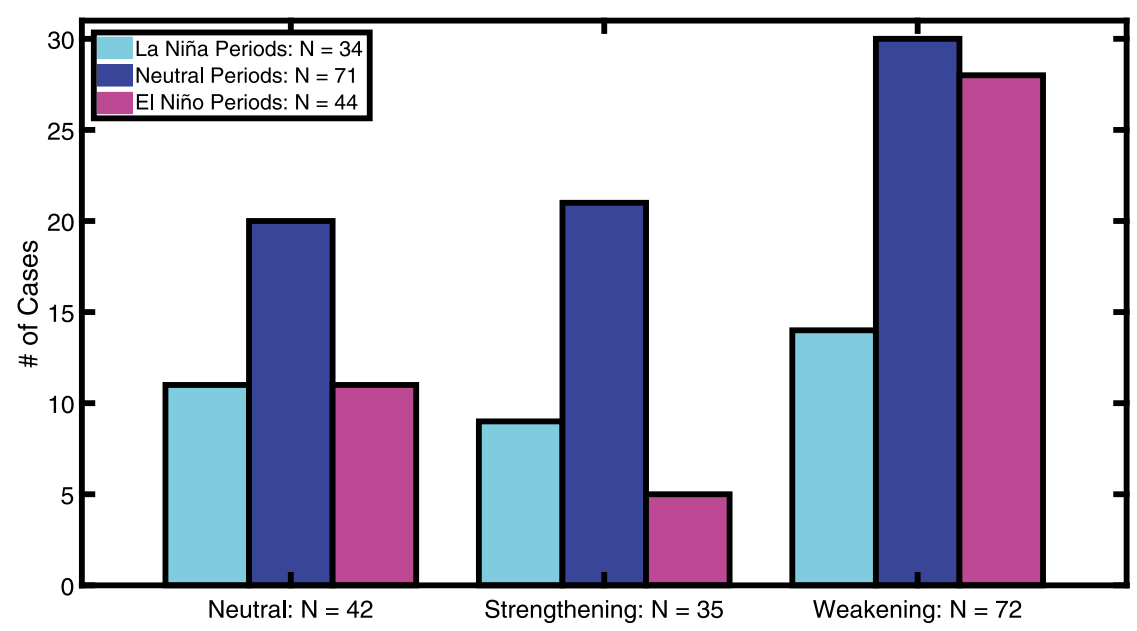

FIG. 6. The number of MJO cases that weaken, strengthen, or have neutral changes over the MC conditioned on the phase of ENSO. La Niña periods are shown with cyan bars, ENSO neutral periods are shown with blue bars, and El Niño periods are shown with magenta bars. This figure is based on the time series of RMM phase and amplitude as well as the ONI from 1974 to 2013.

of statistical significance in the $\mathrm{SH}$ of the MC is driven by the presence of both positive and negative MSE anomalies in the SH. The north-south dipole signature in both the SST and MSE datasets reflects the coupling between MSE and SST. Positive SST anomalies will generate enhanced latent and sensible heat fluxes, both of which lead to an increase in MSE (e.g., Wang and Sobel 2011 and references therein). Aside from the north-south variations described above, Fig. 7 also shows that MSE is generally higher across most of the MC for cases in which the MJO strengthens over the MC.

Warmer SSTs and enhanced MSE in the SH of the $\mathrm{MC}$ result in increased precipitation in the $\mathrm{SH}$ for MJOs that weaken over the MC compared to those that strengthen. Figure 8 shows statistically significant positive daily precipitation anomalies in the $\mathrm{SH}$ for MJOs that weaken over the MC compared to those that strengthen. On average, precipitation in the $\mathrm{SH}$ is $2.10 \mathrm{~mm}^{-1}$
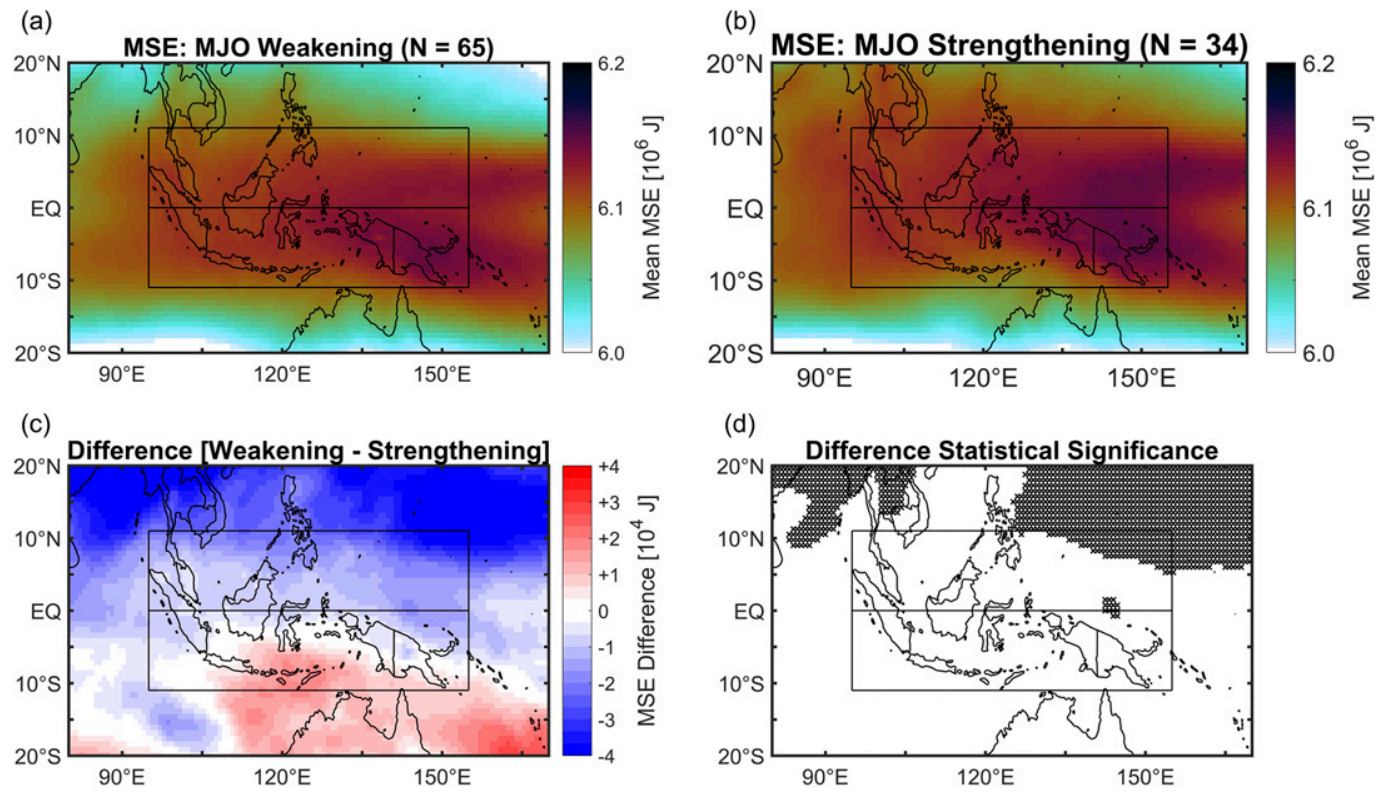

FIG. 7. As in Fig. 5, but for the mean column-integrated MSE. 
(a)

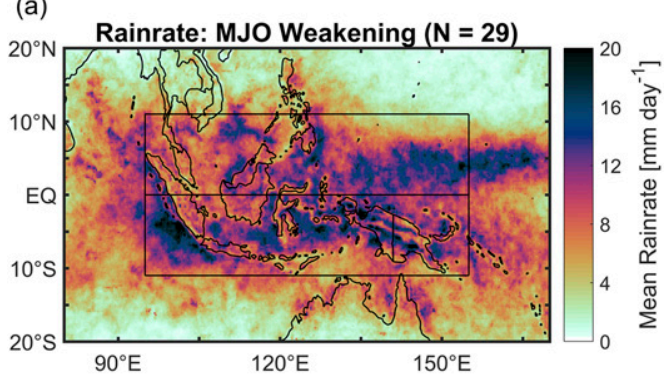

(c)

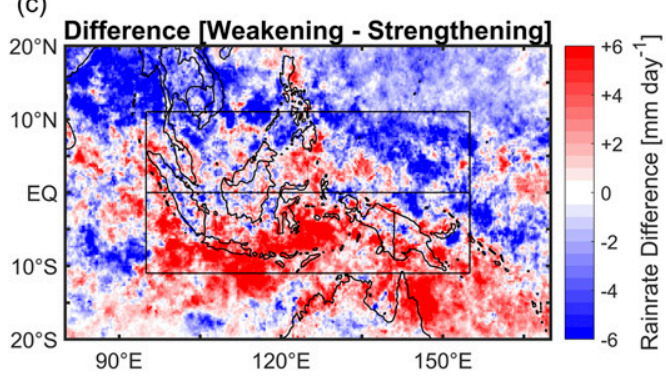

(b)

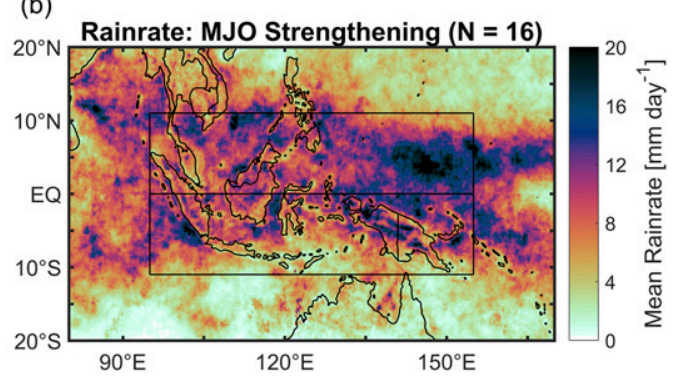

(d)

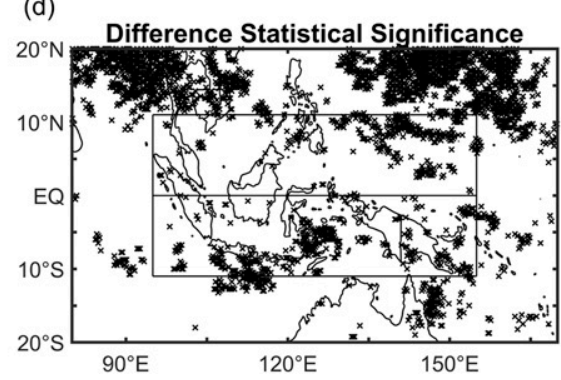

FIG. 8. As in Fig. 5, but for the mean rain rate.

higher for $\mathrm{MJO}$ weakening cases. In contrast, precipitation in the $\mathrm{NH}$ of the $\mathrm{MC}$ is $1.44 \mathrm{~mm}_{\text {day }}{ }^{-1}$ lower on average. Both mean differences are statistically different from 0 at $p=0.05$ and many points in the SH have statistically significant differences between MJO weakening and strengthening cases. Similar to the SST differences, statistically significant rain-rate differences in the SH of the MC are prominent in the Java and Banda Seas south of Borneo. Similar patterns are observed for precipitation frequency (not shown). The higher frequency of precipitation and mean rain rates in the $\mathrm{SH}$ of the $\mathrm{MC}$ are reflected in positive 200-hPa divergence anomalies in the same area (Fig. 9). Mean divergence values are positive $\left(+0.88 \times 10^{-6} \mathrm{~s}^{-1}\right)$ in the $\mathrm{SH}$ and negative $\left(-0.65 \times 10^{-6} \mathrm{~s}^{-1}\right)$ in the $\mathrm{NH}$ for MJO cases that weaken over the MC compared to those that strengthen. Both mean values are statistically different from 0 . Finally, statistically significant negative daily precipitation anomalies for MJO weakening cases are found north of $10^{\circ} \mathrm{N}$ across much of our broader study domain, consistent with colder SSTs and reduced column-integrated MSE in the same area (Figs. 5 and 7).

\section{$b$. Interpretation of the large-scale patterns}

Across all of the large-scale variables we examined a consistent north-south dipole was found when comparing MJOs in which the RMM index weakens over the $\mathrm{MC}$ against those in which it strengthens. MJOs that weaken over the MC are found to occur with warmer SSTs and higher column-integrated MSE in the SH. Both variables are strongly correlated with enhanced precipitation, consistent with our finding of more frequent precipitation, higher accumulations, and enhanced upper-level divergence in the $\mathrm{SH}$ for MJOs that weaken over the MC. Zhang and Dong (2004) documented the southward shift in MJO precipitation during $\mathrm{NH}$ winter and the northward shift during $\mathrm{NH}$ summer. The north-south dipole in SSTs and MSE is suggestive of a seasonal cycle in the probability that the MJO will strengthen or weaken across the MC.

To investigate this further, we plot the annual variability of MJO cases that weaken, strengthen, or have neutral changes across the MC in Fig. 10. Figure 10 was generated using the full 1974-2013 time series of the RMM index. Figure 10 again demonstrates that most MJOs weaken across the MC, particularly during the $\mathrm{NH}$ winter (roughly November-February). However, there is a window during NH summer (JulyOctober) when the RMM index almost always strengthens or at least maintains its intensity as the MJO propagates across the MC. The number of weakening and strengthening MJO events in each month of the year is also shown in Fig. S8 of the supplemental material. Of the $35 \mathrm{MJO}$ events in our database that strengthen over the MC, only 10 occur from December to March (NH winter). Likewise, only 4 of the $72 \mathrm{MJO}$ weakening events occurred during a comparable 4-month window (July-October) in the $\mathrm{NH}$ summer. Controlling for the strength of the MJO as it approaches the $\mathrm{MC}$ by constraining the phase $3 \mathrm{am}-$ plitude to be between 1 and 1.5 does not alter this general seasonal cycle (section 3e). 
(a)

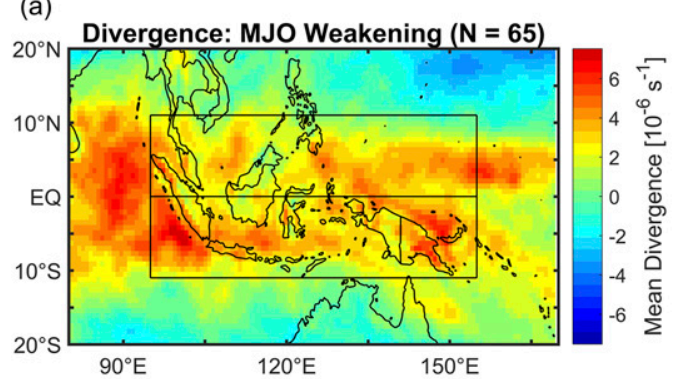

(c)

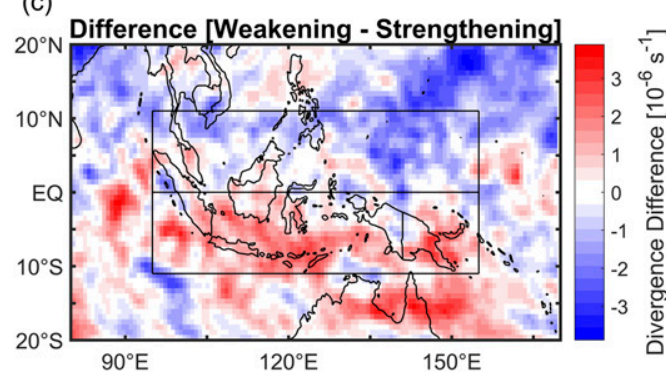

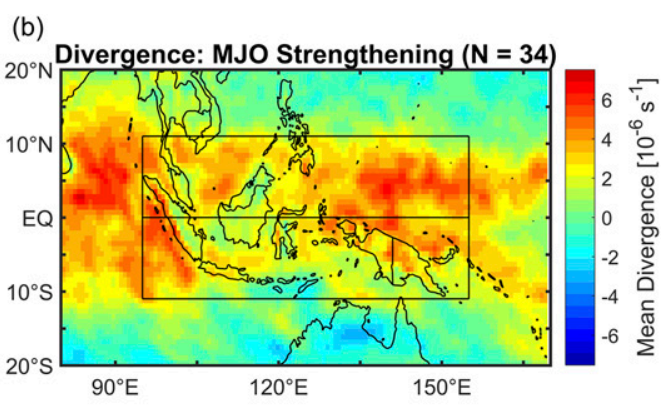

(d)

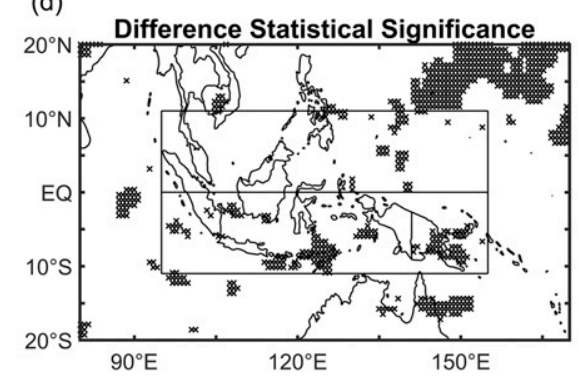

FIG. 9. As in Fig. 5, but for the mean 200-hPa divergence.

The seasonal cycle in MJO strengthening or weakening over the MC is consistent with our analysis of the large-scale environmental variables. $\mathrm{NH}$ winter is characterized in general by a southward shift in the warmest SSTs and hence MSE. The convective envelope from MJOs that approach and cross the MC during this season will follow the warmer SSTs and heightened MSE and shift south off the equator into the SH of the
MC (e.g., Zhang and Dong 2004). This is reflected in the enhanced precipitation and upper-level divergence in the $\mathrm{SH}$ for MJOs that weaken over the MC (which preferentially occur during the $\mathrm{NH}$ winter). In contrast, MJOs that approach the MC during the $\mathrm{NH}$ summer will follow the warmer SSTs and heightened MSE and cross the MC north of the equator, consistent with positive precipitation anomalies in the $\mathrm{NH}$ (shown in Fig. $8 \mathrm{c}$ as

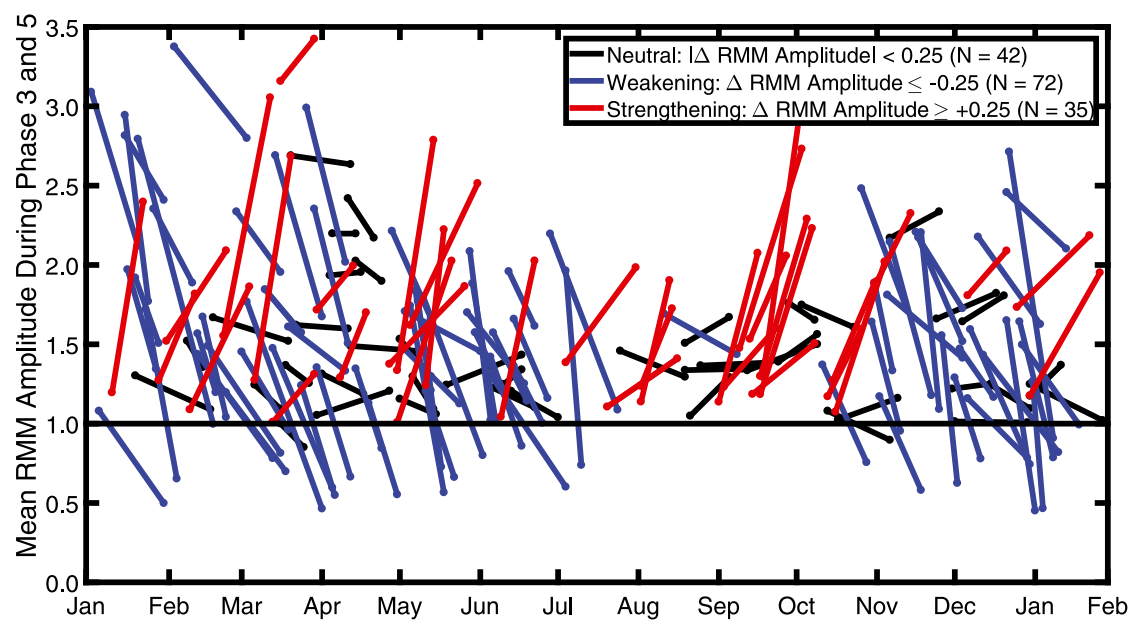

FIG. 10. The annual distribution of MJO weakening (blue lines) and strengthening (red lines) events over the MC based on the time series of RMM phase and amplitude from 1974 to 2013. The black lines are for events in which the phase-mean RMM amplitude changed by less than 0.25 between phases 3 and 5 . The sample sizes for all classifications are given in the legend. 


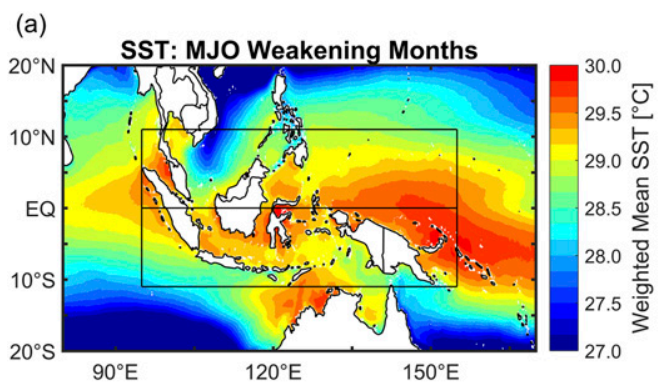

(c)

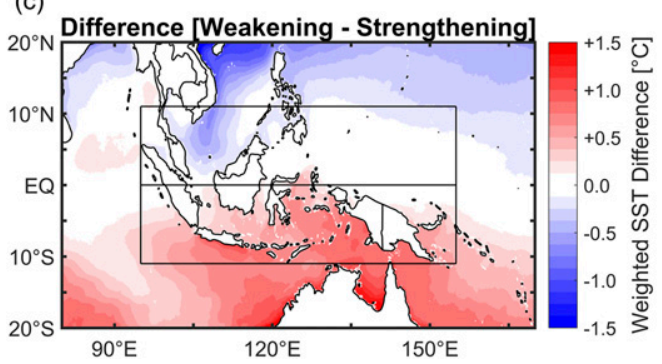

negative values given our weakening minus strengthening plotting format) for MJOs that strengthen over the MC.

We can also evaluate the impact of the seasonal cycle by comparing the mean SSTs for MJO weakening and strengthening events against the seasonal cycle in SSTs over the MC. To do this, we computed a weighted mean SST using the frequency of MJO weakening and strengthening events in each month and the annual cycle in monthly mean SSTs. For example, consider a scenario with 15 total MJO weakening events, where 5 events occurred in January and 10 events occurred in July. To compute the mean SST for MJO weakening, we would add 5 times the mean SST in January and 10 times the mean SST in July and divide the sum by 15 . By comparing the weighted SST for MJO weakening months with the weighted SST for MJO strengthening months we can evaluate the impact of the seasonal cycle. Figure 11 shows the results of this analysis. The difference in MJO weakening and strengthening events using this methodology (Fig. 11c) is strikingly similar to the difference in composite SST maps examined previously (Fig. 5c). This illustrates that the dominant signal in our analysis is a seasonal cycle in the likelihood that the MJO strengthens or weakens over the MC.

While acknowledging that the majority of MJO episodes occur during the $\mathrm{NH}$ winter and spring, the seasonal pattern of MJO strengthening and weakening over the MC provides an important, and to this point, undocumented aspect for understanding MJO-MC interactions. Our analysis demonstrates that, according to

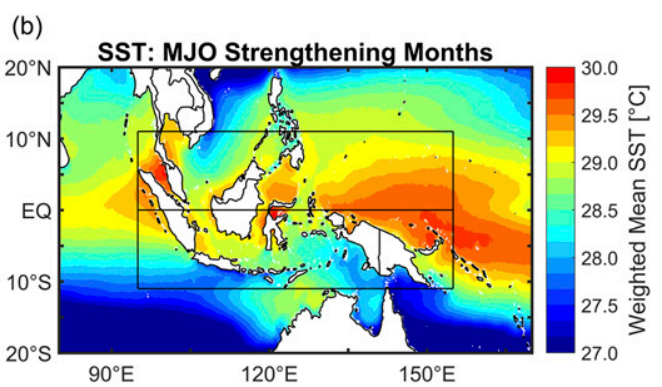

FIG. 11. Weighted composites of monthly mean SST. (a) The monthly mean SSTs weighted by the annual cycle of MJO weakening events, (b) the mean weighted by the annual cycle of MJO strengthening events, and (c) the difference. Comparing this figure with Fig. 5 illustrates the seasonal cycle in MJO strengthening and weakening over the MC.

the global RMM index, the MJO tends to weaken when the main convective envelope associated with an MJO crosses the MC primarily in the SH. In contrast, when the convective envelope crosses in the $\mathrm{NH}$ the MJO tends to intensify or at least maintain its initial intensity as it crosses the MC. The SH of the MC is characterized by more (1.6 times the land fraction) and taller (1.4 times the mean elevation) islands compared to the $\mathrm{NH}$ (Fig. 1). Our analysis suggests that this geographical difference is associated with MJO weakening over the $\mathrm{MC}$ when it crosses in the $\mathrm{SH}$, a finding that is consistent with previous analyses of MJO interactions with the MC. In some cases the boreal summer intraseasonal oscillation (BSISO; Lee et al. 2013), part of the Asian monsoon, may aid in the propagation of the MJO across the MC, although the exact impact is unclear. Of the $18 \mathrm{MJO}$ strengthening events occurring during $\mathrm{NH}$ summer, roughly $61 \%$ occurred with a BSISO index amplitude $>1$. However, an equal $63 \%$ of MJO weakening events during the $\mathrm{NH}$ summer co-occurred with a BSISO index amplitude $>1$. Thus, the impact of BSISO on the strengthening or weakening of the MJO across the MC during $\mathrm{NH}$ summer is unclear.

\section{c. Evaluation using a precipitation-based MJO metric}

Our analysis up until this point has been based on changes in the amplitude of the RMM index as the MJO crosses the MC. As mentioned in the data and methods section, the RMM index is a metric that reflects the global strength of the MJO, particularly the response of the upper-level wind field. Its primary benefit for our study is its widespread usage and easy interpretability. 


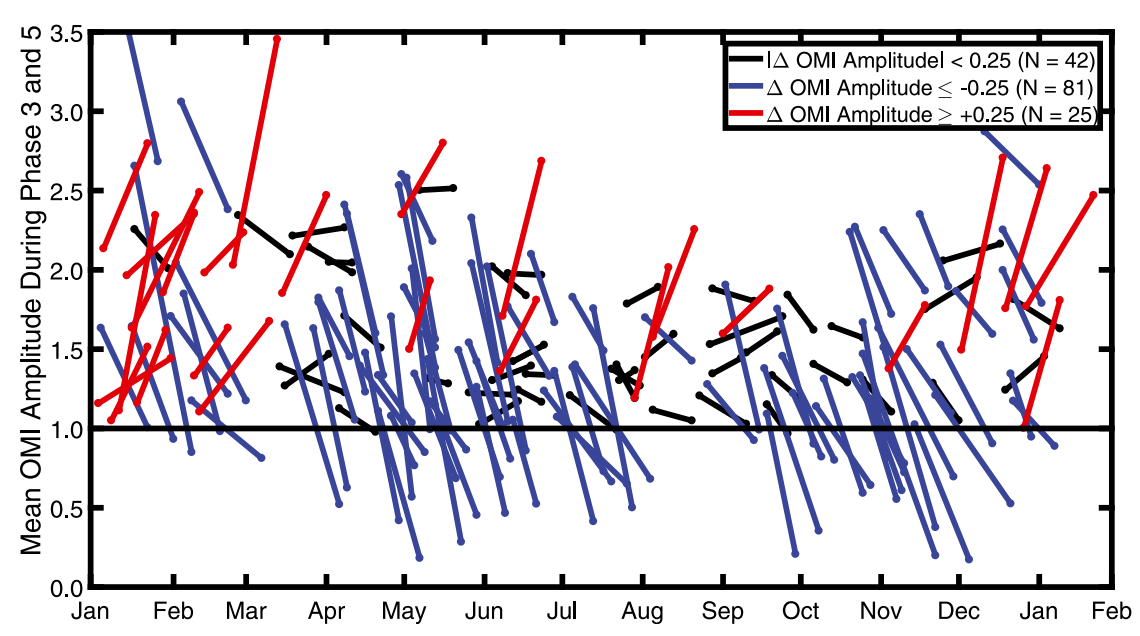

FIG. 12. As in Fig. 10, but for the time series of OMI phase and amplitude from 1979 to 2016.

However, given that the localized precipitation patterns over the MC have been hypothesized as a key factor of MJO-MC interactions, it makes sense to extend our analysis to focus on changes in precipitation over the MC. For this reason, we repeated the analysis using an MJO phase and amplitude metric that is based on the local precipitation signal-the OLR MJO index (OMI; Kiladis et al. 2014). Because it is based on spatial patterns of OLR, the OMI more directly reflects the changes in precipitation as the MJO progresses across the MC. We repeated our method for identifying MJO strengthening and weakening events across the MC using the OMI instead of the RMM index. All thresholds (i.e., $\Delta$ OMI amplitude $\geq 0.25$ ) and phases were maintained.

As with the RMM index, the OMI shows that the MJO most often weakens over the MC, although the ratio of MJO weakening to strengthening is closer to 3:1 using the OMI compared to 2:1 using the RMM index. The seasonal cycle of changes in the OMI is shown in Fig. 12. The seasonal cycle of MJO weakening using the OMI is more complex compared to the RMM-based seasonal cycle (Fig. 10). Consistent with the RMM index, the OMI shows that the MJO most often maintains its intensity and can strengthen if it crosses the MC during the NH summer (August-September; Fig. 12). However, the OMI also identifies several cases of MJO strengthening during the $\mathrm{NH}$ winter. $\mathrm{MJO}$ weakening in the OMI is predominant during the $\mathrm{NH}$ spring and fall. An analysis of the monthly evolution of OLR anomalies associated with the MJO provides a potential explanation for this pattern. Figure 13 shows the mean OMI-phase-4 OLR anomaly for each month as well as the weighted latitude of the OLR anomaly. The weighted latitude tracks the centroid of the OLR anomaly during each month and reflects how far off of the equator the center of convection deviates as the MJO crosses the MC. In addition to showing an expected seasonal cycle in the strength of the MJO (with stronger MJOs preferentially occurring during NH winter), Fig. 13 also shows that the OLR anomaly becomes more negative (i.e., the precipitation associated with the MJO intensifies) as the MJO deviates farther off of the equator. The seasonal north-south migration of the MJO convective envelope may explain the patterns in Fig. 12. As the MJO crosses the MC closer to the equator in $\mathrm{NH}$ spring and fall, the OMI shows that the MJO most often weakens. During periods when the convective envelope deviates off of the equator (i.e., $\mathrm{NH}$ summer and winter) precipitation associated with the MJO can sometimes intensify over the MC.

\section{d. Comparison with previous results}

Our finding that the MJO tends to weaken when it crosses the MC close to the equator ( $\mathrm{NH}$ spring and fall) and may intensify when it crosses during $\mathrm{NH}$ winter and summer is broadly consistent with previous results. Several papers provide possible explanations for this result. Hagos et al. (2016) demonstrated that the diurnal cycle of solar radiation and subsequent convection over the islands of the MC could have a stalling effect on the propagation of the MJO. An alternate explanation comes from Kim et al. (2014), who showed that the meridional advection of MSE ahead of the MJO convective envelope was a key driver of MJO propagation. Along the equator and in the $\mathrm{SH}$ of the $\mathrm{MC}$ the presence of more and taller islands would limit both the generation (via a reduction of latent heat fluxes off the ocean surface) and advection (via terrain blocking) of MSE ahead of the MJO. Wu and Hsu (2009) documented the 


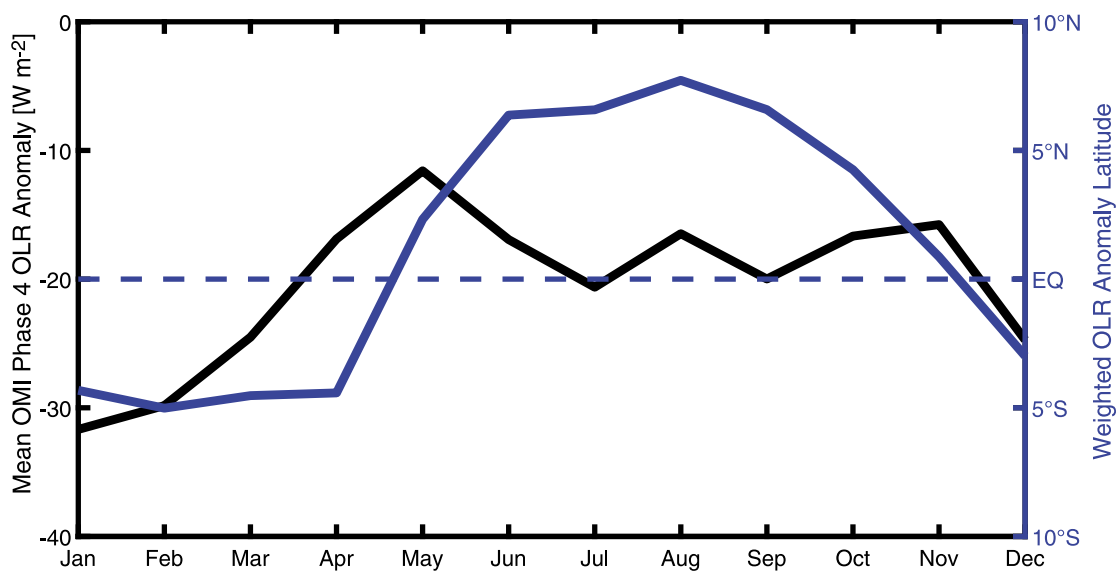

FIG. 13. The annual cycle of the mean negative OLR anomaly (black line, left $y$ axis) during OMI phase 4 and the weighted latitude of the negative anomaly over the MC (blue line, right $y$ axis) based on the time series of OMI phase and amplitude from 1979 to 2014.

influence of the topography in the $\mathrm{MC}$ on the eastward propagation of the MJO. The $\mathrm{Wu}$ and Hsu topographic effects would be stronger for the taller and larger islands of the $\mathrm{SH}$ compared to the $\mathrm{NH}$ of the MC.

Two other papers examining MJO-MC interactions warrant further discussion. KC16 used a precipitationtracking approach based on TRMM data to characterize $\mathrm{MJO}$ events that crossed the MC and compared them to MJO events that stalled over the MC. While the $\mathrm{KC16}$ algorithm may not capture MJO-related precipitation features that propagate in a discontinuous manner but nonetheless may be associated with a coherent MJO circulation, they did find that MC-crossing MJO events are most likely to occur in December and that more MCcrossing events occur during La Niña conditions compared to El Niño conditions. It is not possible to directly compare our findings with theirs for two primary reasons: 1 ) we are examining MJO events that strengthen or weaken over the MC as opposed to those that cross or stall. An MJO that is able to cross the MC in the $\mathrm{KC16}$ tracking dataset may nevertheless be substantially weaker on the far side; and 2) $\mathrm{KC1} 16$ did not run their tracking algorithm on all MJOs throughout the year, but rather focused on the time period from mid-September to March. Consistent with their finding that $33 \%$ of their stalling MJOs did not reach the threshold for an MJO in the RMM index, most of the stalling MJOs they sampled are unclassifiable using our RMM-based strengthening or weakening framework. Of their crossing events that were classifiable using our approach, 50\% (10/20) strengthened over the MC while $35 \%$ (7/20) weakened. Their choice to focus on the most frequent MJO time window also means that we cannot indirectly validate our seasonal cycle result using their dataset.
A second recent paper, ZL17, also tracked the MJO precipitation signal across the $\mathrm{MC}$ as a method for examining MJO-MC interactions. They found that slightly more MJOs stall over the MC during NH summer (17/29 vs $15 / 36$ during $\mathrm{NH}$ winter). While they do identify MJOs that weaken across the MC they do not report a seasonal cycle in MJO weakening, which would be more comparable to our current analysis. Those caveats being established, there are nonetheless aspects of those papers that corroborate our findings. The non-MCcrossing $\mathrm{MJO}$ events in the $\mathrm{KC16}$ dataset tended to cluster along and slightly south of the equator whereas the crossing MJO events in their dataset were more evenly distributed meridionally (see their Fig. 10). In the ZL17 dataset, MJOs that cross the MC deviate well off the equator during both $\mathrm{NH}$ winter and summer (see their Fig. 10). The southward deviation during $\mathrm{NH}$ winter is larger than the mean deviation during $\mathrm{NH}$ summer. The MSE available to the MJO decreases with increasing latitude (Figs. 7a,b) and therefore their finding that the MJO has to detour farther off of the equator in the SH may explain our finding that the RMM index most often weakens when the MJO crosses the MC in the $\mathrm{SH}$.

\section{e. Controlling for initial intensity}

Figure 10 suggests that weakening MJOs tend to occur with higher starting intensities (as gauged by the phase- 3 amplitude of the RMM index) compared to MJOs that strengthen over the MC. This could be problematic for our analysis if this sampling difference is the reason for the seasonal cycle described in section $3 \mathrm{~b}$. The strongest MJOs preferentially occur during $\mathrm{NH}$ winter. To quantify the impact of this, we 


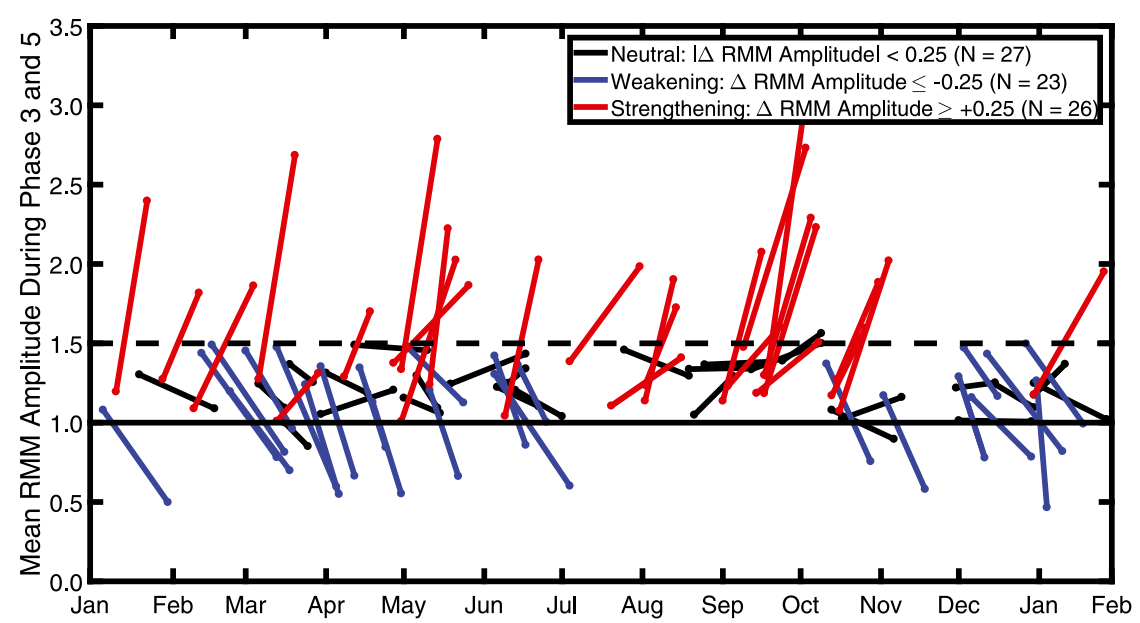

FIG. 14. As in Fig. 10, but limiting the maximum phase 3 RMM amplitude to 1.5 to constrain the initial intensity of the MJO entering the MC.

subset the MJOs in our dataset to contain only those whose phase-3 RMM amplitude was between 1.0 and 1.5. MJOs in this "constrained initial intensity" analysis are shown in Fig. 14. The seasonal cycle in MJO strengthening and weakening persists for MJOs with constrained initial intensities. Strengthening MJOs continue to dominate during the NH summer. Examining the mean variable maps for the constrained initial intensity subset adds further confidence in this result (see Figs. S9-S11 in the supplemental material). While the statistical significance that was present using the full dataset mostly disappears after subsampling, the north-south dipole in each variable persists. Importantly, mean SSTs in the SH are warmer than weakening cases (Fig. 15) and moist static energy in the far northern part of our domain is statistically larger for MJO strengthening cases compared to those that weaken (Fig. S9). The net result is that we have confidence that the seasonal cycle of RMM index strengthening and weakening is robust even when controlling for variance in the strength of the MJO as it approaches the MC. (a)

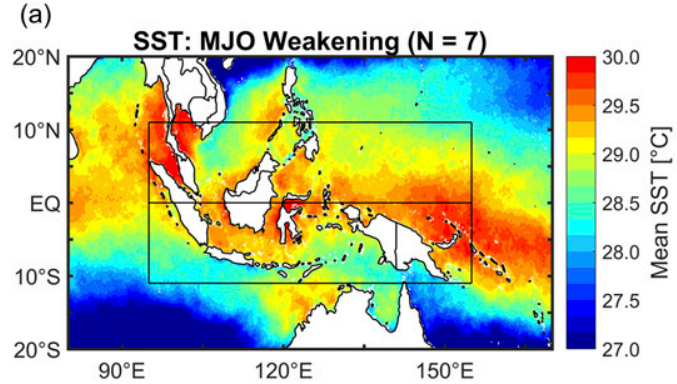

(c)

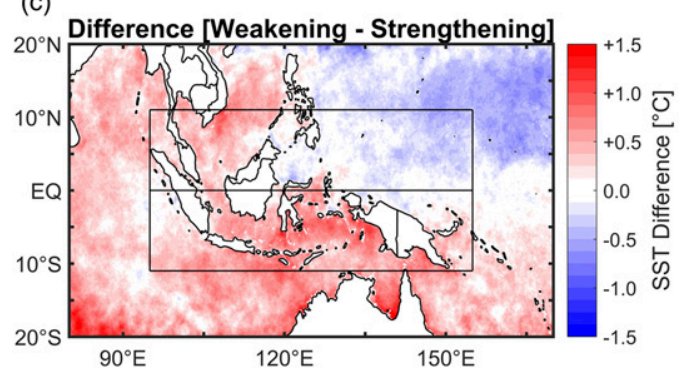

(b)

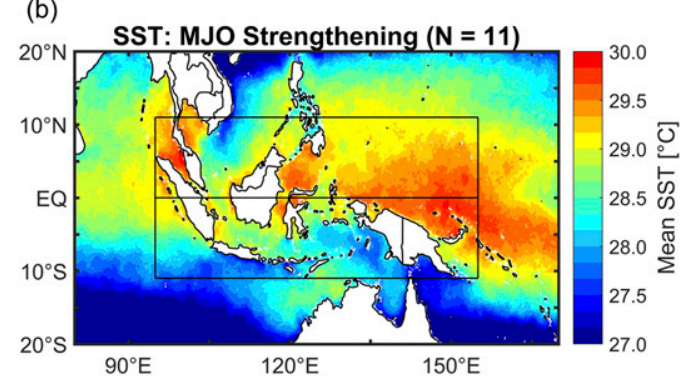

(d)

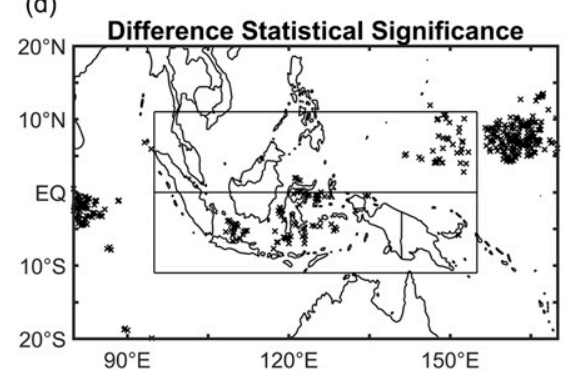

FIG. 15. As in Fig. 5, but limiting the maximum phase 3 RMM amplitude to 1.5 to constrain the initial intensity of the MJO entering the MC. 


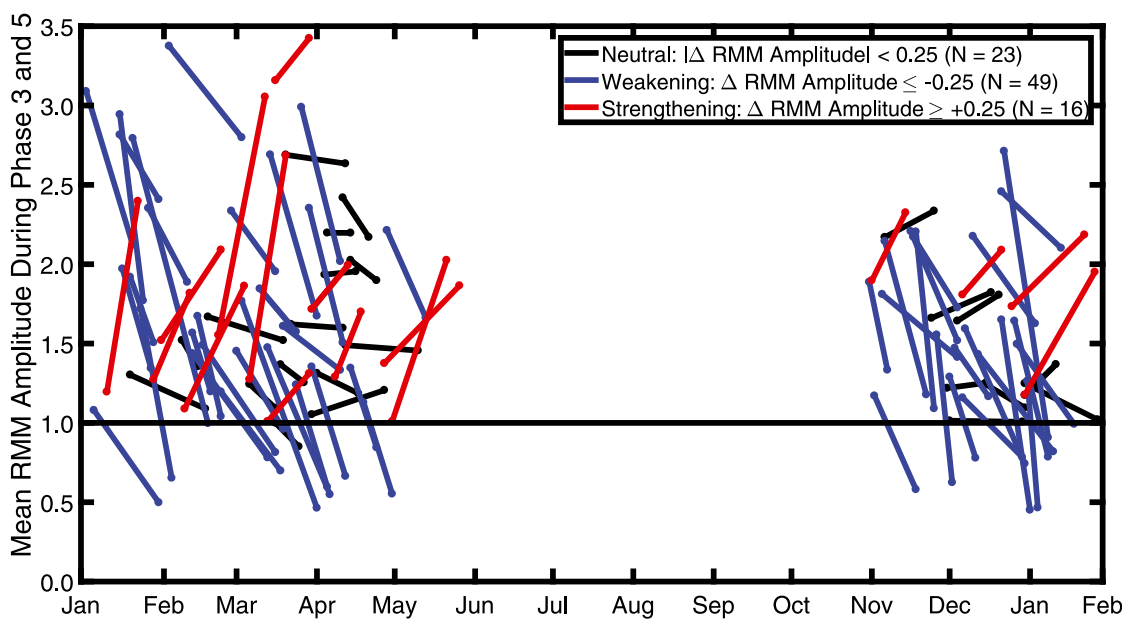

FIG. 16. As in Fig. 10, but restricting the time window to November-April to remove the seasonal cycle.

\section{f. Moving beyond the seasonal cycle}

The dominant signal in our analysis of the large-scale environmental conditions associated with strengthening and weakening MJOs was the seasonal cycle, which expressed itself as a persistent north-south dipole in every variable we examined. While acknowledging that this is a key result, we also attempted to push beyond this finding to probe for more secondary effects. For example, the month of May contains both MJOs that strengthen and weaken over the MC and the difference between them within a single month cannot plausibly be explained by a seasonal cycle. To remove the impact of the seasonal cycle we limited our sampling to include only MJO events that approached the MC from November through April, in effect limiting the seasonal north-south variability in SSTs. The annual distribution of MJO transitions in our "no seasonal cycle" framework is shown in Fig. 16.

The smaller sample size resulting from cutting the original dataset in half manifests as a lack of coherent statistical significance in any of the large-scale fields examined (Fig. 17 and Figs. S12-15 in the supplemental material). There are signals hinting that SSTs are warmer in the western MC for MJO cases that weaken over the MC and that weakening MJOs in general have less precipitation and weaker upper-level divergence when exiting the MC, but the lack of significance means these results should be interpreted cautiously. The only field that has both spatial coherency and (albeit limited) statistical significance is the column-integrated MSE (Fig. 17). Weakening MJOs generally occur with lower MSE everywhere over the MC, and statistically significant negative MSE anomalies occur in a band centered on the equator north of New Guinea $\left(\sim 135^{\circ}-155^{\circ} \mathrm{E}\right)$ and east of the center of MJO convection during RMM phase 4 (Fig. 2c). The colder SSTs in the eastern MC likely reflect the impact of ENSO. Of the MJO strengthening events in this no-seasonal cycle framework, $41 \%$ occurred during El Niño periods and 27\% occurred during La Niña periods. The opposite is true for the MJO strengthening events where only $19 \%$ occurred during El Niño periods and $31 \%$ occurred during La Niña periods. The colder SSTs in the eastern MC for El Niño periods likely translate into reduced MSE for MJO weakening events.

\section{Conclusions}

We set about to add to the growing body of literature on the interaction between the MC and the eastward propagation of the MJO. Our approach is geared toward answering a straightforward question: some MJO events strengthen over the MC while many others weakenWhat are the large-scale environmental characteristics (SST, MSE, precipitation, and upper-level divergence) of strengthening and weakening MJOs that could plausibly explain the difference? We use changes in the amplitude of the RMM index from phase 3 (when the MJO is approaching the MC) to phase 5 (when the MJO is exiting the MC) to identify strengthening and weakening MJO events. Using this basic classifier, we composite a variety of environmental variables for strengthening and weakening MJO cases and evaluate the differences between the composite fields. The primary results of our analysis are as follows:

1) The MJO weakens over the MC at least twice as often as it strengthens. While only weak MJOs can strengthen over the MC, being weak in phase 3 is 
(a)

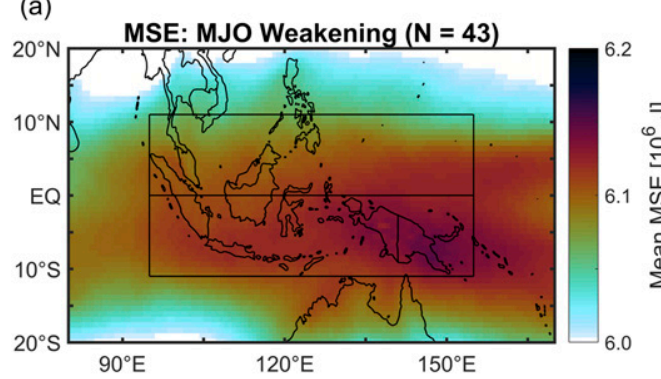

(c)

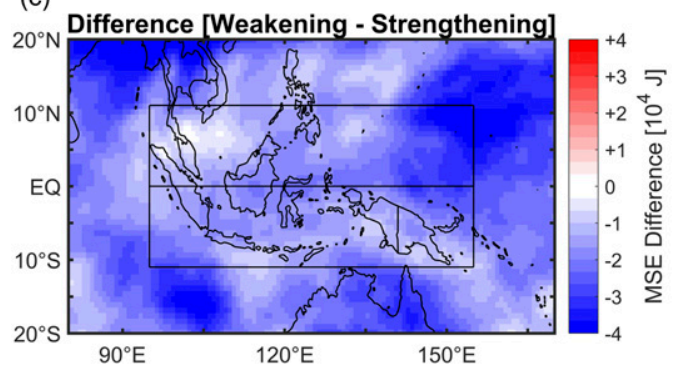

(b)

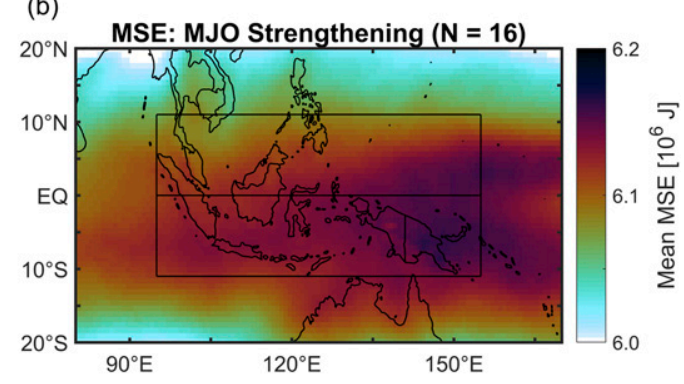

(d)

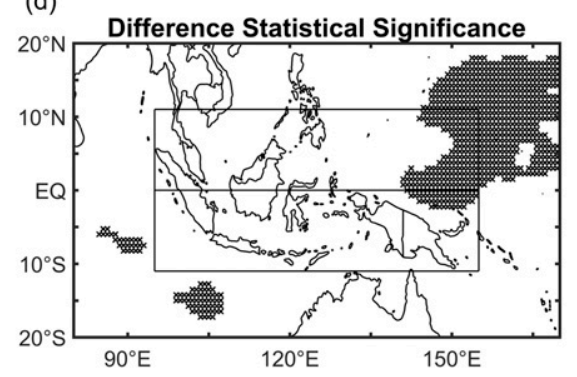

FIG. 17. As in Fig. 7, but restricting the time window to November-April to remove the seasonal cycle.

not a reliable predictor of subsequent strengthening. Weakening MJOs are twice as likely to occur during El Niño years compared to La Niña years and the reverse is true for strengthening MJOs.

2) Weakening MJOs, according to the global RMM index, tend to occur with large positive SST and column-integrated MSE anomalies in the SH of the MC. This corresponds to positive MJO precipitation and upper-level divergence anomalies in the $\mathrm{SH}$. This north-south dipole in all variables examined reflects a seasonal cycle in the probability that the MJO strengthens or weakens over the MC. There is a window in late $\mathrm{NH}$ summer and fall in which the RMM index almost always strengthens over the MC. When the MJO crosses the MC in the SH (most commonly during $\mathrm{NH}$ winter), the previously documented mechanisms for MJO weakening may be more easily engaged because there is more and taller topography there. These patterns are robust even after controlling for variance in the intensity of MJOs approaching the MC. Analysis of an OLR-based MJO index (OMI) revealed that precipitation associated with the MJO can intensify during both $\mathrm{NH}$ winter and summer when the MJO deviates off of the equator.

3) We attempted to remove the seasonal cycle to look for other forcing mechanisms beyond the seasonal north-south migration of SSTs. After removing the seasonal cycle, weakening MJOs were characterized by lower MSE across the entire MC, but statistically significant MSE differences only occurred in the eastern edge of the MC. Lower sample sizes after removing the seasonal cycle resulted in a lack of statistical significance in most fields, so these results should be interpreted with caution.

Our finding that the MJO has a seasonal preference for strengthening and weakening over the $\mathrm{MC}$ is a new and important contribution in the search for physical mechanisms underpinning MJO-MC interactions. ZL17 posed two necessary criteria for explanations of the MC barrier effect on the MJO: 1) that any reasonable explanation should reflect specific aspects of the MC (viz., its mountainous terrain and "intricate land-sea distributions") and 2) that the explanation should be able to explain why some MJOs are able to cross or intensify across the MC while others do not. Our finding that MJOs with an RMM index that weakens over the MC tend to have larger precipitation anomalies in the $\mathrm{SH}$ of the MC satisfies the first criteria. The elevated terrain and higher land fraction in the $\mathrm{SH}$ would engage a number of hypothesized mechanisms for weakening the MJO. For example, Hagos et al. (2016) demonstrated that the diurnal cycle of convection and associated cloudiness over land can have a stalling effect on MJO propagation. Another paper, Kikuchi and Wang (2008), showed that the amplitude of the diurnal cycle of precipitation over the $\mathrm{MC}$ was larger during $\mathrm{NH}$ winter compared to $\mathrm{NH}$ summer. This enhanced diurnal cycle is one possible physical explanation for why the MJO tends to weaken when crossing the $\mathrm{MC}$ during $\mathrm{NH}$ winter. Our finding of a seasonal cycle in the probability 
that the MJO strengthens or weakens across the MC partially satisfies the second ZL17 criteria. When the main convective envelope associated with the $\mathrm{MJO}$ crosses the $\mathrm{MC}$ well off of the equator the $\mathrm{MJO}$ is more likely to intensify or at minimum maintain its strengththus overcoming the barrier effect.

However, our analysis methodology is unable to answer a new question raised by our study that would have to be answered to completely satisfy the second ZL17 criteria-why some MJOs within a given season or month strengthen while others weaken. This remaining question might be better investigated using modeling case studies of individual events occurring within a given season. These focused modeling studies will enable a more robust, physical understanding of the cause of MJO weakening during NH winter. That work is left for future studies. Our finding of a seasonal cycle in the ability of the MJO to strengthen over the MC also provides support for extending the sampling period for future MJO-MC campaigns to sample MJOs interacting with the MC in all seasons. In this sense, the Years of the Maritime Continent (YMC) international program that is scheduled to take place over a multiyear period from 2017 to 2019 will be particularly valuable for complementing and expanding previous studies that focused on a more limited time window (e.g., the AMIE/DYNAMO campaign).

Acknowledgments. This research is based on work supported by the U.S. Department of Energy, Office of Science, Biological and Environmental Research as part of the Atmospheric System Research (ASR) Program. The Pacific Northwest National Laboratory is operated for DOE by Battelle Memorial Institute under Contract DE-AC06-76RLO 1830. Samson Hagos had support from the National Oceanic and Atmospheric Administration under Grant NOAA-OAR-CPO-2017-2004896. Daehyun Kim was supported by the Korea Meteorological Administration Research and Development Program under Grant KMIPA 2016-6010. Interpolated OLR data were provided by the NOAA/OAR/ESRL PSD, Boulder, Colorado, from their website at https://www.esrl.noaa.gov/ psd/data/gridded/data.interp_OLR.html.

\section{REFERENCES}

Adames, Á. F., and D. Kim, 2016: The MJO as a dispersive, convectively coupled moisture wave: Theory and observations. J. Atmos. Sci., 73, 913-941, https://doi.org/10.1175/ JAS-D-15-0170.1.

, J. M. Wallace, and J. M. Monteiro, 2016: Seasonality of the structure and propagation characteristics of the MJO. J. Atmos. Sci., 73, 3511-3526, https://doi.org/10.1175/ JAS-D-15-0232.1.
Dee, D. P., and Coauthors, 2011: The ERA-Interim reanalysis: Configuration and performance of the data assimilation system. Quart. J. Roy. Meteor. Soc., 137, 553-597, https://doi.org/ 10.1002/qj.828.

Feng, J., T. Li, and W. Zhu, 2015: Propagating and nonpropagating MJO events over Maritime Continent. J. Climate, 28, 8430 8449, https://doi.org/10.1175/JCLI-D-15-0085.1.

Hagos, S. M., C. Zhang, Z. Feng, C. D. Burleyson, C. De Mott, B. Kerns, J. J. Benedict, and M. N. Martini, 2016: The impact of the diurnal cycle on the propagation of Madden-Julian oscillation convection across the Maritime Continent. J. Adv. Model. Earth Syst., 8, 1552-1564, https://doi.org/10.1002/ 2016MS000725.

Hirata, F. E., P. J. Webster, and V. E. Toma, 2013: Distinct manifestations of austral summer tropical intraseasonal oscillations. Geophys. Res. Lett., 40, 3337-3341, https://doi.org/ 10.1002/grl.50632.

Huffman, G. J., and Coauthors, 2007: The TRMM Multisatellite Precipitation Analysis (TMPA): Quasi-global, multiyear, combined-sensor precipitation estimates at fine scales. J. Hydrometeor., 8, 38-55, https://doi.org/10.1175/ JHM560.1.

Jia, X.-J., J.-W. Ge, and S. Wang, 2016: Diverse impacts of ENSO on wintertime rainfall over the Maritime Continent. Int. J. Climatol., 36, 3384-3397, https://doi.org/10.1002/ joc. 4562 .

Jiang, X., and Coauthors, 2015: Vertical structure and physical processes of the Madden-Julian oscillation: Exploring key model physics in climate simulations. J. Geophys. Res. Atmos., 120, 4718-4748, https://doi.org/10.1002/2014JD022375.

Kerns, B. W., and S. S. Chen, 2016: Large-scale precipitation tracking and the MJO over the Maritime Continent and IndoPacific warm pool. J. Geophys. Res. Atmos., 121, 8755-8776, https://doi.org/10.1002/2015JD024661.

Kikuchi, K., and B. Wang, 2008: Diurnal precipitation regimes in the global tropics. J. Climate, 21, 2680-2696, https://doi.org/ 10.1175/2007JCLI2051.1.

Kiladis, G. N., J. Dias, K. H. Straub, M. C. Wheeler, S. N. Tulich, K. Kikuchi, K.M. Weickmann, and M. J. Ventrice, 2014: A comparison of OLR and circulation-based indices for tracking the MJO. Mon. Wea. Rev., 142, 1697-1715, https://doi.org/ 10.1175/MWR-D-13-00301.1.

Kim, D., and Coauthors, 2009: Application of MJO simulation diagnostics to climate models. J. Climate, 22, 6413-6436, https://doi.org/10.1175/2009JCLI3063.1.

_, J.-S. Kug, and A. H. Sobel, 2014: Propagating versus nonpropagating Madden-Julian oscillation events. J. Climate, 27, 111-125, https://doi.org/10.1175/JCLI-D-13-00084.1.

—, H. Kim, and M.-I. Lee, 2017: Why does the MJO detour the Maritime Continent during austral summer? Geophys. Res. Lett., 44, 2579-2587, https://doi.org/10.1002/2017GL072643.

Kim, H.-M., D. Kim, F. Vitart, V. E. Toma, J.-S. Kug, and P. J. Webster, 2016: MJO propagation across the Maritime Continent in the ECMWF Ensemble Prediction System. J. Climate, 29, 3973-3988, https://doi.org/10.1175/JCLI-D-15-0862.1.

Lee, J.-Y., B. Wang, M. C. Wheeler, X. Fu, D. E. Waliser, and I.- S. Kang, 2013: Real-time multivariate indices for the boreal summer intraseasonal oscillation over the Asian summer monsoon region. Climate Dyn., 40, 493-509, https://doi.org/ 10.1007/s00382-012-1544-4.

Liebmann, B., and C. A. Smith, 1996: Description of a complete (interpolated) outgoing longwave radiation dataset. Bull. Amer. Meteor. Soc., 77, 1275-1277. 
Liu, F., T. Li, H. Wang, L. Deng, and Y. Zhang, 2016: Modulation of boreal summer intraseasonal oscillation over the western North Pacific by the ENSO. J. Climate, 29, 7189-7201, https:// doi.org/10.1175/JCLI-D-15-0831.1.

Maloney, E. D., and A. H. Sobel, 2004: Surface fluxes and ocean coupling in the tropical intraseasonal oscillation. J. Climate, 17, 4368-4386, https://doi.org/10.1175/JCLI-3212.1.

Raymond, D. J., 2001: A new model of the Madden-Julian oscillation. J. Atmos. Sci., 58, 2807-2819, https://doi.org/10.1175/ 1520-0469(2001)058<2807:ANMOTM > 2.0.CO;2.

Reynolds, R. W., and T. M. Smith, 1994: Improved global sea surface temperature analyses using optimum interpolation. J. Climate, 7, 929-948, https://doi.org/10.1175/1520-0442(1994)007<0929: IGSSTA $>2.0 . \mathrm{CO} ; 2$.

Rui, H., and B. Wang, 1990: Development characteristics and dynamic structure of tropical intraseasonal convection anomalies. J. Atmos. Sci., 47, 357-379, https://doi.org/10.1175/ 1520-0469(1990)047<0357:DCADSO > 2.0.CO;2.

Salby, M. L., and H. H. Hendon, 1994: Intraseasonal behavior of clouds, temperature, and motion in the tropics. J. Atmos. Sci., 51, 2207-2224, https://doi.org/10.1175/1520-0469(1994)051<2207: IBOCTA $>2.0 . C O ; 2$.

Seo, K.-H., W. Wang, J. Gottschalck, Q. Zhang, J.-K. E. Schemm, W. R. Higgins, and A. Kumar, 2009: Evaluation of MJO forecast skill from several statistical and dynamical forecast models. J. Climate, 22, 2372-2388, https://doi.org/10.1175/ 2008JCLI2421.1.

Sobel, A., and E. Maloney, 2012: An idealized semi-empirical framework for modeling the Madden-Julian oscillation. J. Atmos. Sci., 69, 1691-1705, https://doi.org/10.1175/ JAS-D-11-0118.1.
— and - 2013: Moisture modes and the eastward propagation of the MJO. J. Atmos. Sci., 70, 187-192, https://doi.org/ 10.1175/JAS-D-12-0189.1.

,,-- G. Bellon, and D. M. Frierson, 2008: The role of surface heat fluxes in tropical intraseasonal oscillations. Nat. Geosci., 1, 653-657, https://doi.org/10.1038/ngeo312.

Straub, K. H., 2013: MJO initiation in the real-time multivariate MJO index. J. Climate, 26, 1130-1151, https://doi.org/10.1175/ JCLI-D-12-00074.1.

Vitart, F., and F. Molteni, 2010: Simulation of the Madden-Julian oscillation and its teleconnections in the ECMWF forecast system. Quart. J. Roy. Meteor. Soc., 136, 842-855, https://doi.org/ 10.1002/qj.623.

Wang, S., and A. H. Sobel, 2011: Response of convection to relative sea surface temperature: Cloud-resolving simulations in two and three dimensions. J. Geophys. Res., 116, D11119, https:// doi.org/10.1029/2010JD015347.

Wheeler, M. C., and H. H. Hendon, 2004: An all-season real-time multivariate MJO index: Development of an index for monitoring and prediction. Mon. Wea. Rev., 132, 1917-1932, https://doi.org/ 10.1175/1520-0493(2004)132<1917:AARMMI>2.0.CO;2.

Wu, C.-H., and H.-H. Hsu, 2009: Topographic influence on the MJO in the Maritime Continent. J. Climate, 22, 5433-5448, https://doi.org/10.1175/2009JCLI2825.1.

Zhang, C., and M. Dong, 2004: Seasonality in the Madden-Julian oscillation. J. Climate, 17, 3169-3180, https://doi.org/10.1175/ 1520-0442(2004)017<3169:SITMO>2.0.CO;2.

—_, and J. Ling, 2017: Barrier effect of the Indo-Pacific Maritime Continent on the MJO: Perspectives from tracking MJO precipitation. J. Climate, 30, 3439-3459, https://doi.org/10.1175/ JCLI-D-16-0614.1. 